Supplement of Nonlin. Processes Geophys., 24, 419-433, 2017

https://doi.org/10.5194/npg-24-419-2017-supplement

(c) Author(s) 2017. This work is distributed under

the Creative Commons Attribution 3.0 License.

(c) (1)

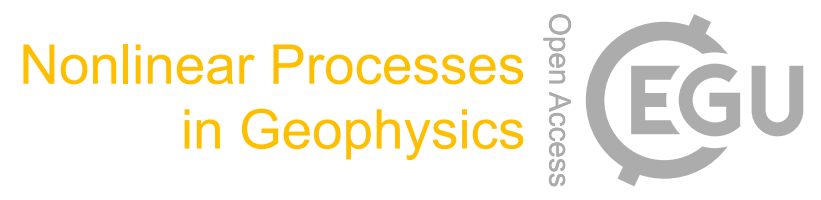

Supplement of

\title{
An upper limit for slow-earthquake zones: self-oscillatory behavior through the Hopf bifurcation mechanism from a spring-block model under lubricated surfaces
}

Valentina Castellanos-Rodríguez et al.

Correspondence to: Castellanos-Rodríguez Valentina (valentina@ cimat.mx)

The copyright of individual parts of the supplement might differ from the CC BY 3.0 License. 
(a) $\Pi_{1}=(0.25,0.8,1.8) \omega=0$

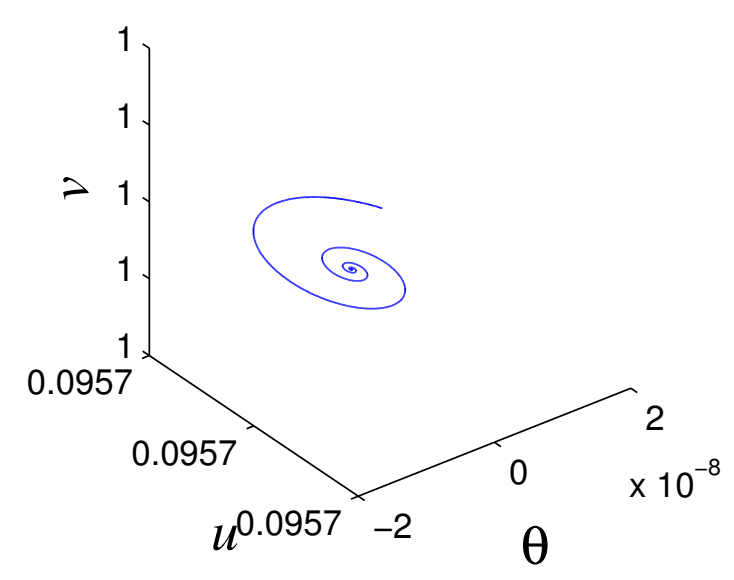

(e) $\Pi_{1} \omega=0$

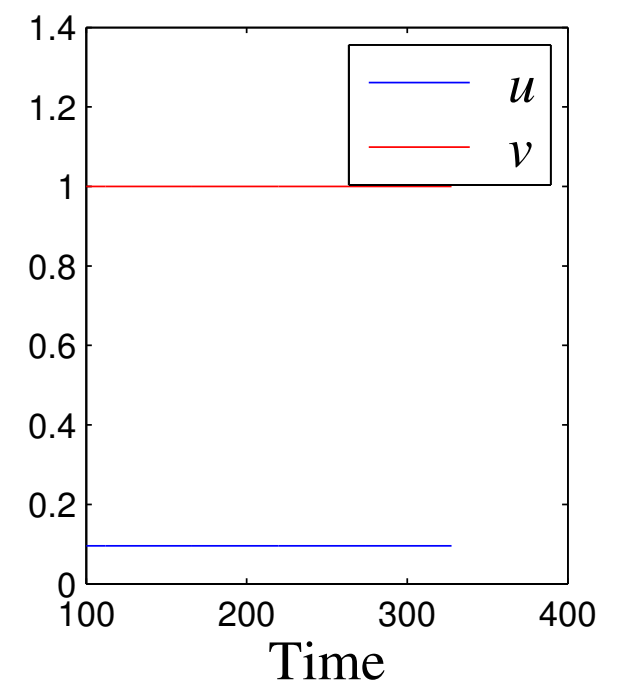

(b) $\Pi_{2}=(0.25,0.8, .5) \omega=0$

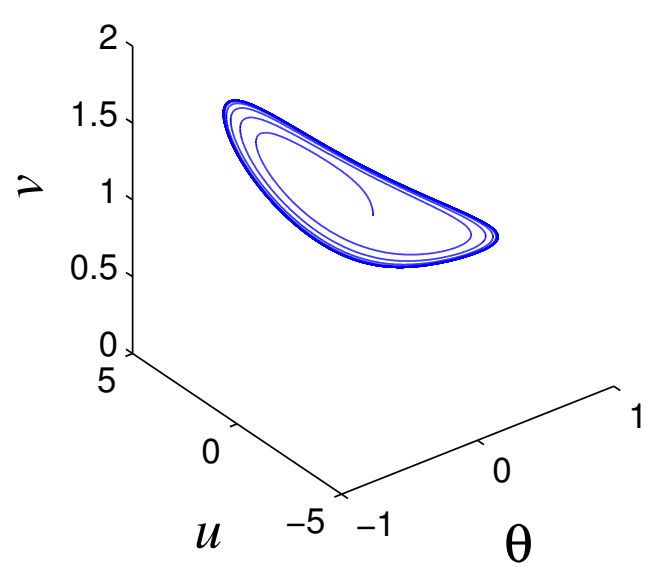

(f) $\Pi_{2} \omega=0$

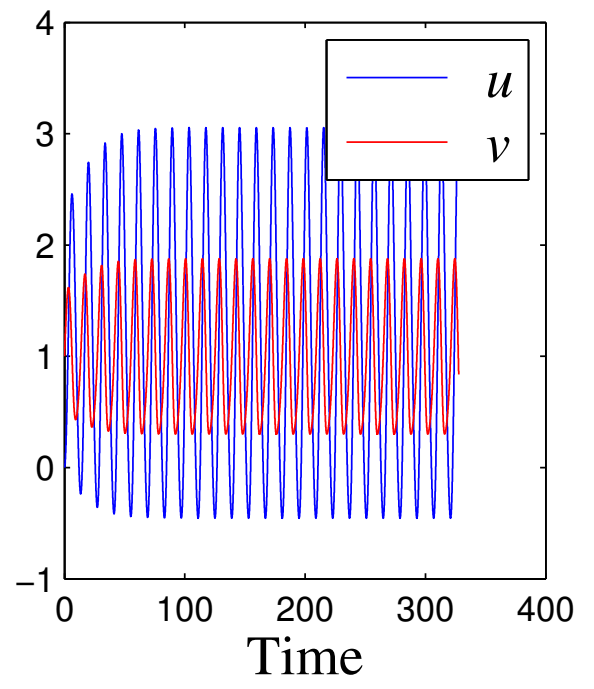

(c) $\Pi_{3}=(0.25,0.8,3) \omega=.1$

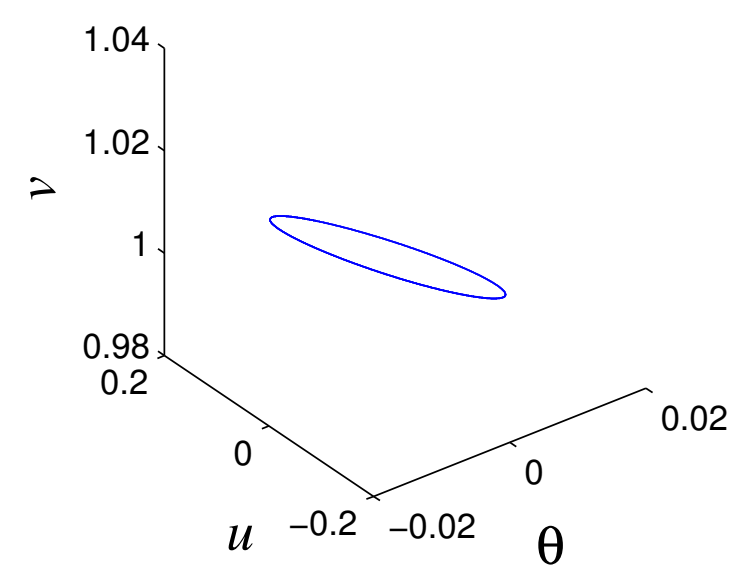

(g) $\Pi_{3} \omega=.1$

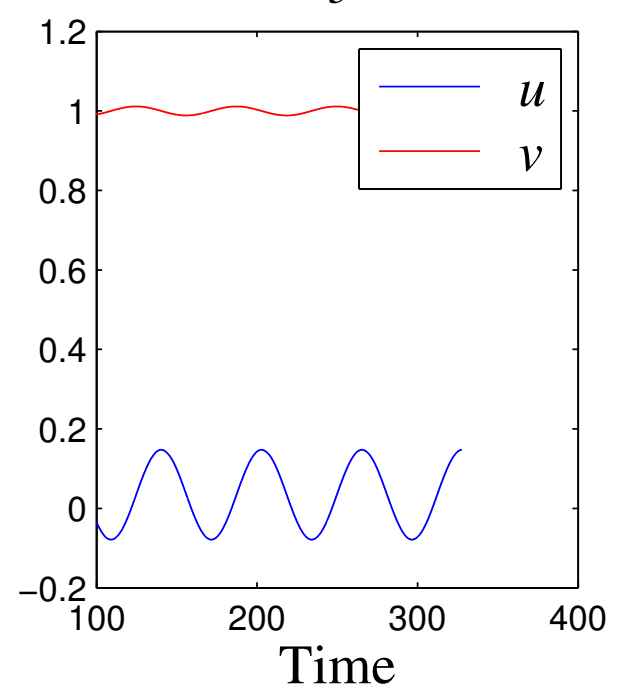

(d) $\Pi_{4}=(0.25,0.8, .5) \omega=.1$

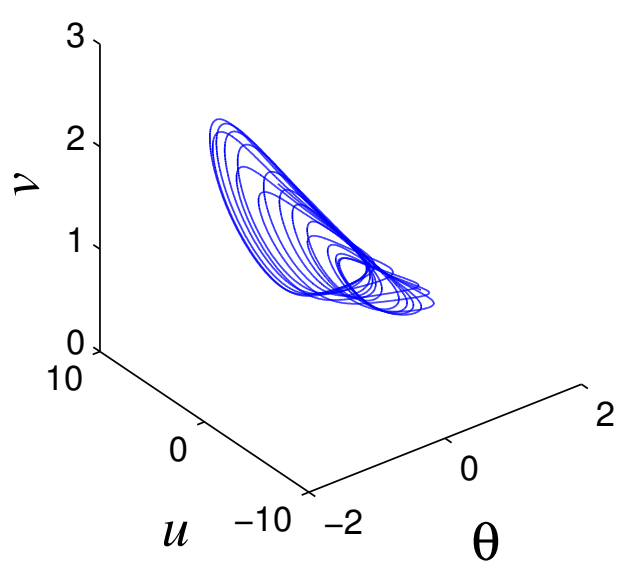

(h) $\Pi_{4} \omega=.1$

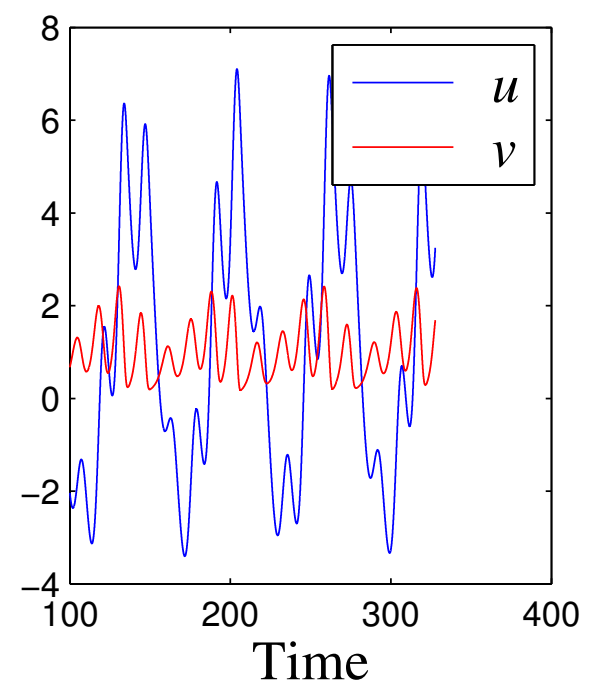

